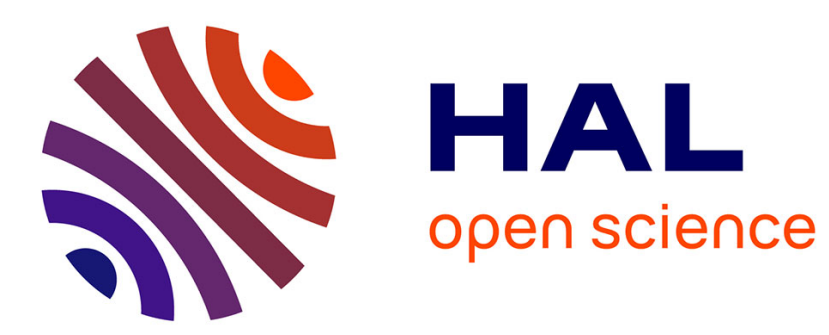

\title{
DYNAMIC FRACTURE OF WELDED JOINTS
}

\author{
J. Giovanola, R. Klopp, S. Kirkpatrick, W. Mcdonald
}

\section{To cite this version:}

J. Giovanola, R. Klopp, S. Kirkpatrick, W. Mcdonald. DYNAMIC FRACTURE OF WELDED JOINTS. Journal de Physique IV Proceedings, 1991, 01 (C3), pp.C3-565-C3-572. 10.1051/jp4:1991379 . jpa-00250524

\section{HAL Id: jpa-00250524 https://hal.science/jpa-00250524}

Submitted on 1 Jan 1991

HAL is a multi-disciplinary open access archive for the deposit and dissemination of scientific research documents, whether they are published or not. The documents may come from teaching and research institutions in France or abroad, or from public or private research centers.
L'archive ouverte pluridisciplinaire HAL, est destinée au dépôt et à la diffusion de documents scientifiques de niveau recherche, publiés ou non, émanant des établissements d'enseignement et de recherche français ou étrangers, des laboratoires publics ou privés. 


\title{
DYNAMIC FRACTURE OF WELDED JOINTS
}

\author{
J.H. GIOVANOLA*, R.W. KLOPP* S.W. KIRKPATRICK* and \\ W.W. MCDONALD** \\ *SRI International, 333 Ravenswood Avenue, Menlo Park, CA 94025 \\ U.S.A. \\ ** White Oak Laboratory, Naval surface warfare Center, silver \\ spring, MD 20903-5000, U.S.A.
}

Cette communication présente une étude expérimentale et analytique de la rupture dynamique de soudures en " $T$ " sur un acier à haute résistance. Un dispositif expérimental permettant d'atteindre des vitesses de déformation de plusieurs milliers de $\mathrm{s}^{-1}$ est conçu. Les conditions expérimentales sont déterminées par ajustement de l'épaisseur de la plaque d'explosif et par la densité ou l'épaisseur du matériau écran. La vitesse initiale mesurée de la plaque d'acier constitue une donnée d'entrée dans un code aux éléments fínis pour calculer les contraintes, les déformations et l'endommagement en fonction du temps dans la zone de rupture. Deux échantillons de tailles différentes ont été expérimentés pour évaluer les effets d'échelle sur les soudures. Pour les deux tailles d'échantillon, les conditions de rupture varient géométriquement. Les résultats expérimentaux sont en accord avec l'analyse basée sur un modèle de rupture ductile statistique, indépendant de la vitesse de déformation. Cet accord suggère que l'endommagement dans les soudures de cet acier est peu sensible à la vitesse de déformation.

\begin{abstract}
This paper presents an experimental and analytical investigation of dynamic fracture of T-shaped welded joints (stiffener on a plate) in a high strength steel. A fracture test was designed in which strain rates of several thousand per second can be reached in the weldment region by loading the specimen with tamped explosive. Test conditions can be reliably controlled by adjusting the thickness of the explosive and the density and thickness of the tamping material. The measured initial specimen plate velocity is used as input for finite element simulations of the experiments to calculate the stress and strain and fracture damage histories in the fracture region. Experiments on two specimen sizes were performed to evaluate the effect of geometric scaling of the size on fracture of the weldments. For the two sizes investigated, fracture conditions scaled geometrically. The experimental results were in good agreement with the results of an analysis that used a rate independent, statically calibrated local fracture model to describe fracture by ductile void growth. This agreement suggests that fracture damage in weldments of this particular steel is not very rate sensitive.
\end{abstract}

\section{1.- Introduction.}

Welding is an essential process in assembling large modern steel structures. Because the metallurgical control achievable in weldments is limited, their mechanical properties may differ from those of the base metal being joined. Thus, weldments may often be weak points of a structure, and it is important to evaluate their fracture resistance under loading conditions that either simulate service loads or represent worst case conditions. This paper describes a fracture experiment designed to test $\mathrm{T}$-shaped welded joints under dynamic loading. The test is used to investigate the effect of weldment size on the conditions for initiation and propagation of dynamic fracture and to support the modeling of fracture in weldments. The following sections present experimental results for tests on two sizes of weldments in a high strength steel and preliminary results of a fracture analysis using a simple ductile fracture model. 


\section{2.- Experimental procedure.}

High strain rates are achieved in the experiment by explosively loading a specimen that consists of a slotted base plate with two symmetrically positioned welded stiffeners (Figure 1a). Each stiffener is rigidly bolted to an independently adjustable fixture, and the specimen plate is bolted to a steel die and a base plate (Figure 1b). The center of the specimen plate between the two slots is loaded with strips of sheet explosive (Detasheet(B) backed by two blocks of tamping material. With this test arrangement, only the center portion of the specimen plate is significantly deformed during the experiments, whereas the portion supported by the die acts as a reaction frame, inducing membrane stresses in the plate.

For the weldment geometry and material combinations we studied, the experiment induces fractures that initiate in the plate heat-affected zone of the weldments and then extend through the plate thickness. The fracture resistance of the weldment is evaluated by adjusting the initial velocity imparted to the plate to bracket the conditions for either partial or complete penetration of the crack through the plate. The initial
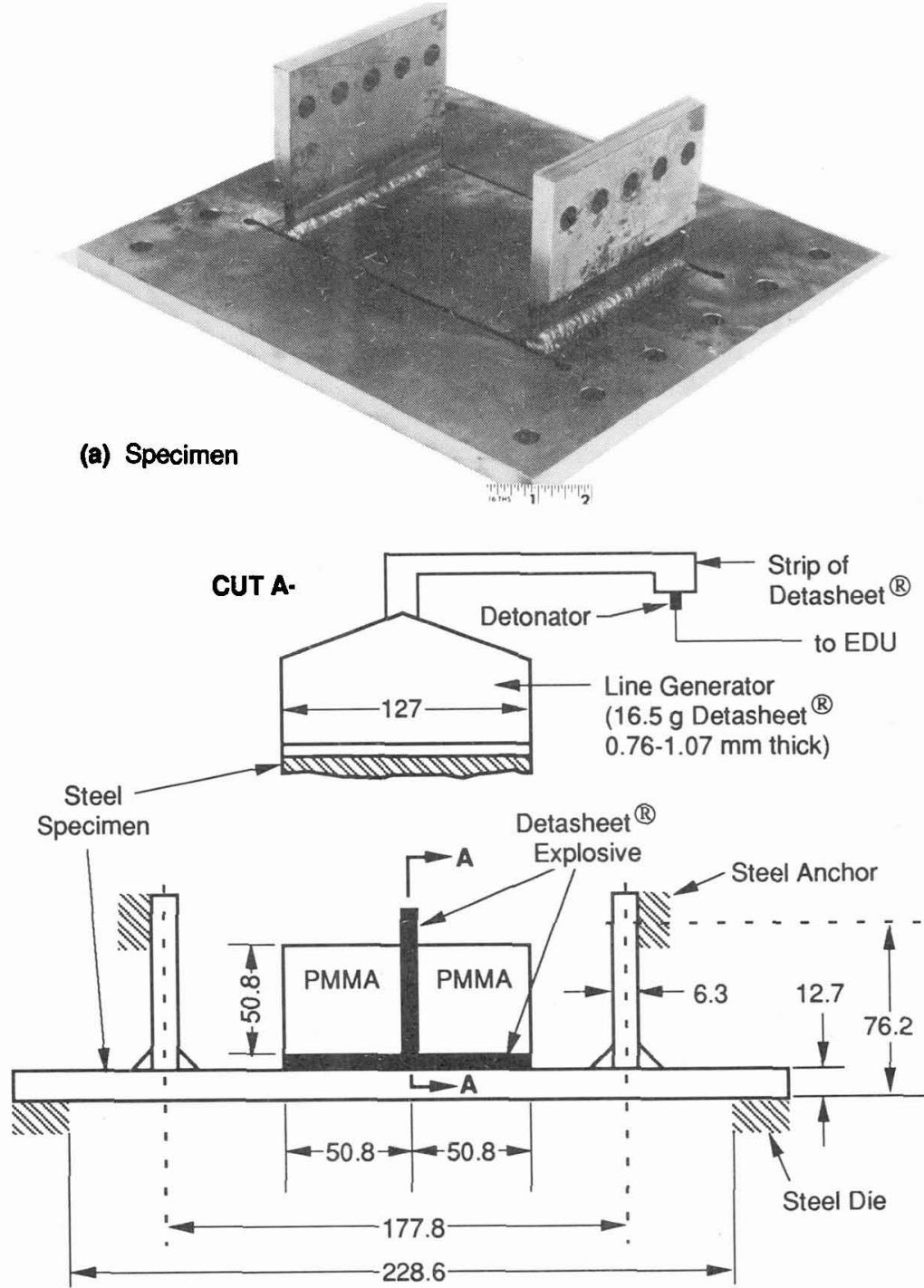

(b) Schematic of explosive loading arrangement (dimensions for large scale specimen shown)

Figure 1. Dynamic fracture experiment for T-shaped weldments. 
velocity is controlled by varying the thickness of the explosive and the thickness and density of the tamping material.

We determine the initial velocity by the plate centerline displacement history measured during the experiment with contact pins. The experimental velocity is used as the initial condition in finite element simulations of the experiments to calculate the stress, strain, and damage histories in the fracture region.

We tested two sizes of specimen, termed large scale and small scale, respectively, with the small scale specimen being half the size of the large scale specimen. Dimensions for the large scale specimen are indicated in Figure 1b. The specimens were prepared from a high strength steel (yield strength $930 \mathrm{MPa}$, ultimate strength $1000 \mathrm{MPa}$, reduction of area $70 \%$ ). The weldments were undermatched, with a weld metal yield strength of approximately $690 \mathrm{MPa}$.

\section{3.- Normalization of specimen structural response.}

To minimize the experimental effort required, it is desirable to be able to predict the influence of specimen size and material properties, explosive specific energy and thickness, and tamping material density and thickness on the initial velocity of the specimen and its structural response. This predictive capability can be achieved by measuring experimentally the plate center deflection histories of one specific type of specimen and then properly normalizing the results.

We derived suitable normalizing parameters for the plate center deflection history by using a simple rigid plastic analysis of the specimen coupled with the Gurney analysis, ${ }^{1}$ which gives an estimate of the initial velocity imparted to the specimen by the explosive gases. The analysis gives the functional dependence of the maximum center plate deflection $\mathrm{d}_{\max }$ and the time at which the deflection is reached $\mathrm{t}_{\max }$, in terms of specimen yield strength $\sigma_{y}$, density $\rho_{p}$, length $L_{p}$, thickness $h_{p}$, and initial plate velocity $V_{0}$. The resulting expressions are

$$
\mathrm{d}_{\max } \sim \frac{\mathrm{L}_{\mathrm{p}}^{2} \rho_{\mathrm{p}}}{\mathrm{h}_{\mathrm{p}} \sigma_{\mathrm{y}}} \mathrm{V}_{0^{2}}
$$

and

$$
t_{\max } \sim \frac{L_{p}^{2} \rho_{p}}{h_{p} \sigma_{y}} V_{0}
$$

The groups of parameters on the right-hand side of Equations (1) and (2) represent the appropriate expressions for normalizing the experimental deflections and the times, respectively.

The initial velocity $V_{0}$ can be expressed as a function of the explosive specific energy $E_{0}$, density $\rho_{e}$, and thickness $h_{e}$ and of the tamping material density $\rho_{\mathfrak{l}}$ and thickness $h_{\mathfrak{l}}$ :

$$
V_{0}=\alpha \sqrt{2 E_{0}}\left[\frac{3}{1+3 \frac{h_{p} \rho_{p}}{h_{e} \rho_{e}}-\left(\frac{2 \frac{h_{p} \rho_{p}}{h_{e} \rho_{e}}}{2 \frac{h_{t} \rho_{t}}{h_{e} \rho_{e}}+1}\right)+\left(1+3 \frac{h_{t} \rho_{t}}{h_{e} \rho_{e}}\right)\left(\frac{2 \frac{h_{p} \rho_{p}}{h_{e} \rho_{e}}}{2 \frac{h_{t} \rho_{t}}{h_{e} \rho_{e}}+1}\right)^{2}}\right]^{1 / 2}
$$

In Equation (3), $\alpha$ is an undetermined coefficient relating the proportion of the specific energy that is converted to kinetic energy of the plate to the total specific energy of the explosive. For the case considered here, we established experimentally that $\alpha=0.645$. 


\section{4.- Experimental results.}

We tested six large scale and four small scale specimens. Fracture conditions were assessed in terms of the explosive thickness needed and the plate center deflection at the instant of crack initiation or complete propagation through the plate. We first bracketed the explosive thicknesses that produced incipient and complete fracture in the large scale specimens; then we scaled those conditions geometrically for the small specimens. Two small scale specimens, S-1 and S-2, did not fracture because of premature deformation and fracture of the test fixture. In all experiments, the center plate deflection history could be fitted well by a second order polynomial. Duplicate experiments (Table 1, experiments L-4 and L-5) indicate that both the structural response and the fracture conditions are quite reproducible. The experimental results are summarized in Table 1 and Figures 2 and 3.

\section{RESULTS OF DYNAMIC FRACTURE EXPERIMENTS}

\begin{tabular}{|c|c|c|c|c|c|}
\hline \multirow[b]{2}{*}{$\begin{array}{l}\text { Expt. } \\
\text { No. }\end{array}$} & \multicolumn{2}{|c|}{$\begin{array}{c}\text { Explosive } \\
\text { (Detasheet) } \\
\end{array}$} & \multirow{2}{*}{$\begin{array}{c}\text { Initial } \\
\text { velocity } \\
(\mathrm{m} / \mathrm{s}) \\
\end{array}$} & \multirow{2}{*}{$\begin{array}{l}\text { Normalized } \\
\text { Plate Center } \\
\text { Deflectlon } \\
\text { "at Fracture" }\end{array}$} & \multirow[b]{2}{*}{ Comments } \\
\hline & $\begin{array}{c}\text { Thlckness } \\
(\mathrm{mm}) \\
\end{array}$ & Type & & & \\
\hline$L-1$ & $\begin{array}{l}2.87 \\
3.05\end{array}$ & $\begin{array}{l}\mathrm{D} \\
\mathrm{C}\end{array}$ & 226 & 1.90 & $\begin{array}{l}\text { Fracture through one } \\
\text { side only; stiffener broke on other side }\end{array}$ \\
\hline $\begin{array}{l}L-2 \\
L-3 \\
L-4 \\
L-5 \\
L-6 \\
S-1\end{array}$ & $\begin{array}{l}1.08 \\
1.63 \\
2.54 \\
2.54 \\
2.98 \\
1.36\end{array}$ & $\begin{array}{l}c \\
c \\
c \\
c \\
c \\
c\end{array}$ & $\begin{array}{l}115 \\
142 \\
187 \\
192 \\
216 \\
211\end{array}$ & $\begin{array}{l}- \\
1.90 \\
1.85 \\
2.24 \\
-\end{array}$ & $\begin{array}{l}\text { No fracture } \\
\text { No fracture } \\
\text { Partial fracture } \\
\text { Pattial fracture } \\
\text { Fracture through both sides } \\
\text { No fracture; abnormal plate anchoring } \\
\text { bolt deformation }\end{array}$ \\
\hline S-2 & 1.65 & c & 235 & - & $\begin{array}{l}\text { Incipient fracture, plate anchoring bolt } \\
\text { fracture }\end{array}$ \\
\hline $\begin{array}{l}S-3 \\
S-4\end{array}$ & $\begin{array}{l}1.65 \\
1.36\end{array}$ & $\begin{array}{l}\mathrm{C} \\
\mathrm{C}\end{array}$ & $\begin{array}{l}234 \\
227\end{array}$ & $\begin{array}{l}2.25 \\
1.98\end{array}$ & $\begin{array}{l}\text { Complete fracture } \\
\text { Partial fracture }\end{array}$ \\
\hline
\end{tabular}

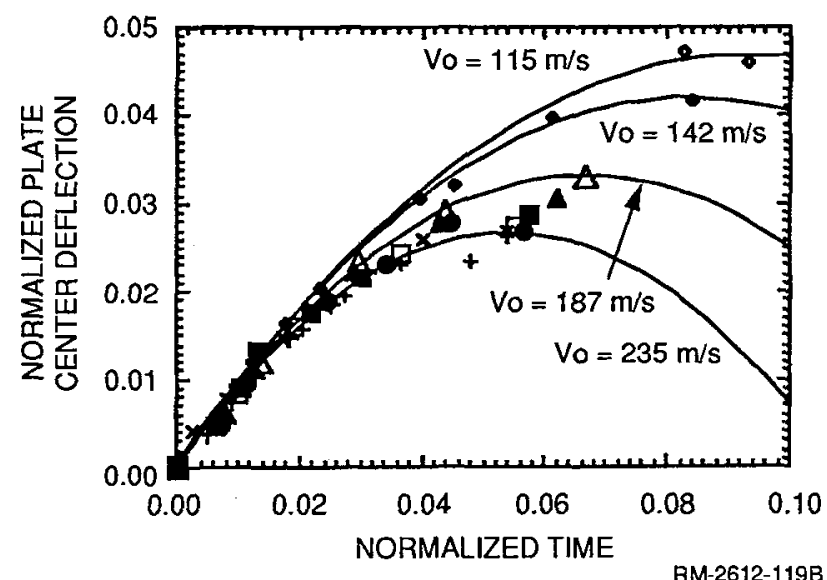

Figure 2. Normalized plate center deflection histories for dynamic fracture experiments. 


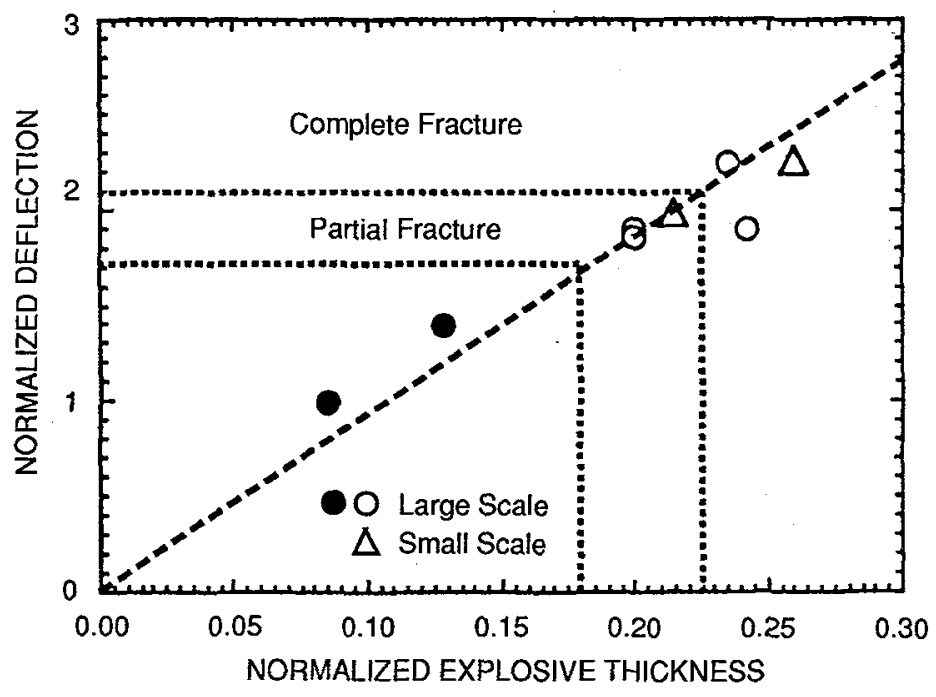

RM-2612-143A

Figure 3. Fracture envelope for high strength steel weldments established on the basis of the dynamic fracture experiments.

(Dashed straight line represents maximum deflection in the absence of fracture.)

Figure 2 plots the normalized deflection history for all 10 specimens tested and represents their structural responses (symbols represent experimental measurements and lines represent second order polynomial fitted through the experimental points). Figure 3 plots the normalized maximum deflection of the specimens as a function of normalized explosive thickness. Both quantities were normalized by the specimen plate thickness. Figure 3 also indicates domains of partial or complete fracture and thus can be regarded as a failure map for the weldments.

Figure 2 shows that the responses of specimens of different scales are appropriately normalized because they reduce to the same curve for identical initial velocities. Figure 2 also shows that during early times the structural response of the specimen is approximately the same for all initial velocities and scales. At later times the specimen response is dependent on the initial velocity, with the curves for higher velocities $(>180 \mathrm{~m} / \mathrm{s})$ apparently tending to a limiting curve.

Finite element simulations show good agreement between the experimental and calculated specimen deflections, thus demonstrating that the measurements performed provide enough information for faithful simulations of the experiments. The simulations also indicate strain rates in the weldment region ranging from 1000 to $5000 \mathrm{~s}^{-1}$ for the range of initial velocities selected in our experiments.

As can be seen in Figure 3, the explosive thickness and center plate deflection at which incipient fracture was induced, normalized by the plate thickness of the specimen, are essentially the same in the large and the small specimens. A similar result holds true for the normalized explosive thicknesses and center plate deflection needed to induce complete plate fracture. On the basis of these (limited) results, we conclude that, to a first approximation, fracture of the explosively loaded steel weldments investigated here follows replica scaling. This observation indicates that most of the energy to fracture is dissipated by plastic deformation of the specimen to nucleate microstructural damage in the weldment region and only a small fraction actually serves to grow the nucleated microstructural damage.

\section{5.- Modeling of weldment fracture.}

The weldment fracture model consists of three components: (1) a geometric and strength model of the weldment, based on metallographic observations and hardness measurements; (2) a strain-based fracture 
model; and (3) a finite element formulation that implements both of the other models. The fracture model is the simplest form of a ductile fracture criterion. ${ }^{2}$ It assumes that failure of a material element of characteristic size $\mathrm{R}_{\text {MIC }}$ occurs once the element has accumulated a critical plastic strain, a function of the state of stress experienced by the element during straining. Mathematically, fracture of the element occurs when

$$
\mathrm{D}=\int \frac{\mathrm{d} \varepsilon_{\mathrm{q}}^{\mathbf{P}}}{\varepsilon_{\mathrm{c}}\left(\sigma_{\text {mean }} / \sigma_{\mathrm{eq}}\right)}=1 \quad \text { over } \mathrm{R}_{\mathrm{MIC}}
$$

where $D$ can be regarded as a normalized damage parameter, $\varepsilon_{\mathrm{cq}}^{\mathrm{P}}$ is the equivalent plastic strain, and $\varepsilon_{\mathrm{c}}\left(\sigma_{\mathrm{mean}} / \sigma_{\mathrm{eq}}\right)$ is the critical failure strain for a given strain triaxiality $\sigma_{\text {mean }} / \sigma_{\mathrm{eq}}$. In its present form the model does not account for a possible strain rate sensitivity of the fracture process and has been calibrated using static data for the failure strain.

We implemented the weldment model and the local fracture criterion into a version of the finite element code DYNA3D, ${ }^{3}$ an explicit nonlinear three-dimensional finite element code for analyzing the large deformation dynamic response of solids and structures. The equations of motion are integrated in time by using the central difference method. Spatial discretization was achieved with eight-node hexahedron (brick) elements. The element size in the fracture region is chosen to represent the material characteristic dimension, $R_{\text {MIC. }}$ To allow fracture of the weldment, a tied node with failure feature was implemented into DYNA3D for the brick elements. This feature requires that node groups have tied degrees of freedom up to the point at which the average damage for the elements associated with the tied node group exceeds the critical value of 1 . Following failure, the nodal constraints are removed and the elements can separate. The material model used in our calculations is a piecewise linear isotropic plasticity model. Integration of the damage function [Equation (4)] occurred within the material constitutive model subroutine. In the finite element calculations, the explosive loading of the specimen was simulated by imposing the experimentally measured initial velocity to the portion of the plate covered by sheet explosive. Figure 4 compares the results of a calculation simulating experiments at an initial velocity of $230 \mathrm{~m} / \mathrm{s}$ with the experimental results for a small scale specimen. The calculated deformed shape of the specimen agrees well with that produced in the experiment. The crack path across the plate is also faithfully reproduced in the simulations. Furthermore, the calculated deflection history was also in good agreement with the experimental measurement. The good agreement between simulations and experiment indicates (1) that a relatively simple ductile fracture model may be sufficient to make predictions of fracture in dynamically loaded structures and (2) that the fracture processes for the steel tested in this investigation are not very strain rate sensitive.

\section{6.- Conclusions.}

The work presented in this paper has yielded the following results and conclusions.

- A simple explosive fracture experiment was developed to test T-shaped weldments at strain rates of several thousand per second. The loading conditions are easily adjustable and yield reproducible results. Measurement of the plate center deflection history is sufficient to provide reliable initial conditions for simulating the experiments.

- A normalization procedure allows extrapolation of the loading conditions for a given specimen size and material to other sizes and materials.

- Tests on two geometrically similar weldments of different sizes, produced with the same welding process, indicate that fracture conditions for the high strength steel investigated are, to a first approximation, size independent.

- A simple rate independent local fracture model for ductile fracture yields correct predictions of the specimen deformations as well as of the crack path and suggests that fracture processes in the weldment investigated are not strain rate sensitive. 


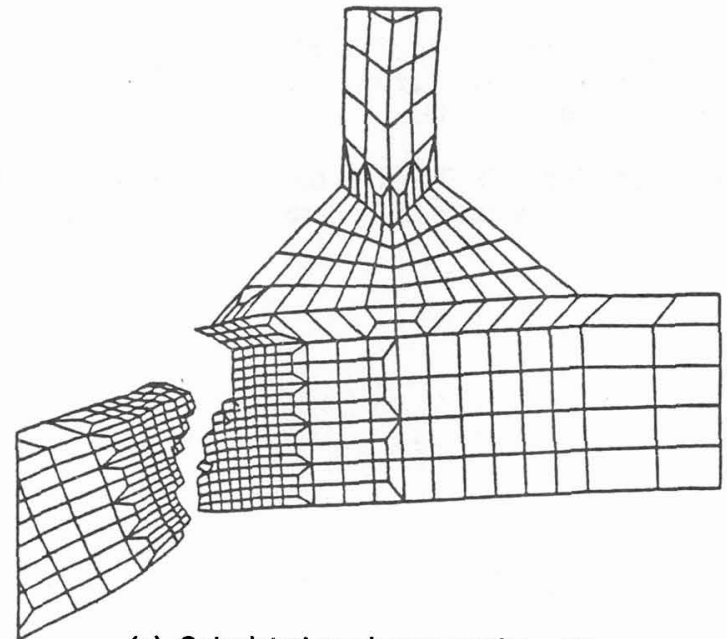

(a) Calculated crack propagation path
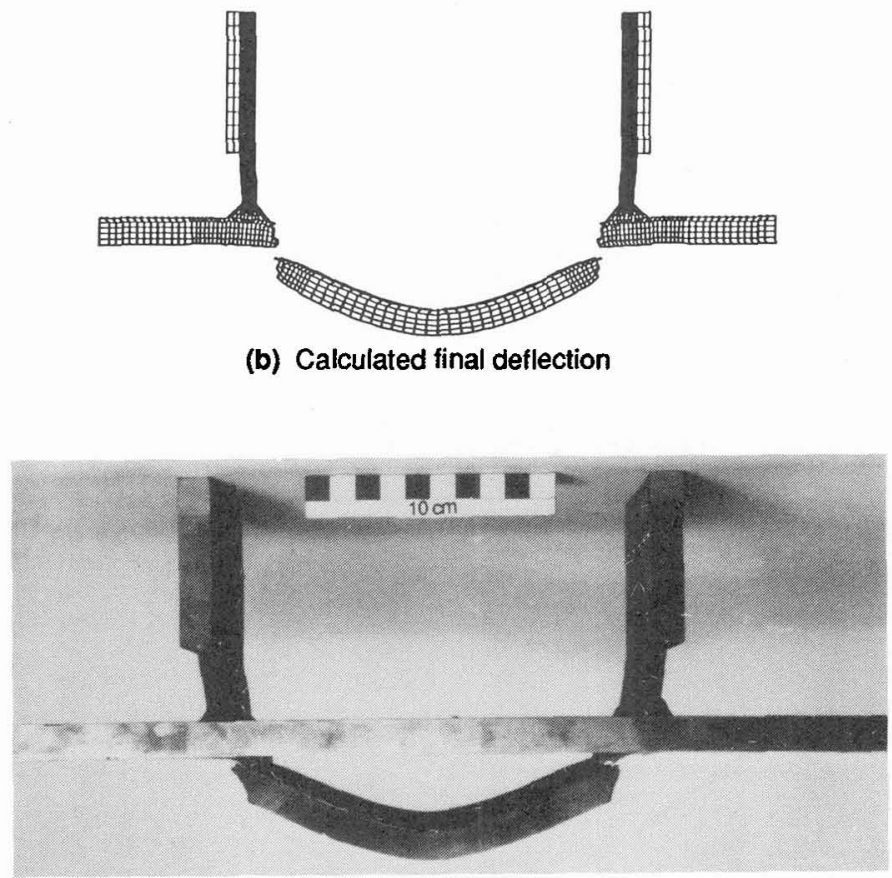

(c) Small scale experiment

CP-317581-2B

Figure 4. Dynamic weld fracture experiment and calculation. 


\section{References.}

/1/ GURNEY, RW, "The Initial Velocities of Fragments from Bombs, Shells, and Grenades" Report No. 405, Ballistic Research Laboratories, Aberdeen Proving Ground, Maryland (1943).

/2/ MUDRY, F, "Methodology and Applications of Local Criteria for Prediction of Ductile Tearing," Elastic-Plastic Fracture Mechanics (L. H. Larson, Ed.), ECSC, EEC, EAEC, Brussels and Luxembourg, Belgium (1985), pp. 263-283.

/3/ HALLQUIST, JO, and WHIRLEY, RG, DYNA3D User's Manual (Nonlinear Dynamic Analysis of Structures in Three Dimensions), Lawrence Livermore National Laboratory, Report UCID-19592, Rev. 2 (1989). 